\title{
Knowledge Regarding Self Care Measures and Quality of Life among Patients with Chronic Renal Failure undergoing Hemodialysis
}

\author{
Sarita Shah, ${ }^{\mathrm{a}, \mathrm{c}}$ Nabin Pokharel ${ }^{\mathrm{b}, \mathrm{d}}$
}

\begin{abstract}
:
Introduction: Chronic Kidney Disease (CKD) affects 500 million people worldwide. In the US there are 1400 per million of estimated prevalence or established renal failure while in the UK it is recorded more than 600 per million in 2007. This study aims to assess the knowledge on self care measured by structured knowledge questionnaire, assess the quality of life measured by WHO QOL-BREF Scale and try to find out the relationship between knowledge of self care measures and quality of life among chronic renal failure patients undergoing haemodialysis. Methods: A non experimental descriptive correlational design with a descriptive approach was used for the study. Non probability, purposive sampling was used to select $95 \mathrm{CRF}$ patients undergoing haemodialysis. The conceptual framework was based on Orem's Self Care Model. The instruments used for data collection were a structured knowledge questionnaire and WHO QOL-BREF Scale. The structured knowledge questionnaire was divided into two sections, sociodemographic variables and knowledge regarding self care measures. The tool was divided into six areas of knowledge such as introduction, clinical features, diagnosis, evaluation, treatment, self care measures and complications of CRF. The main study was conducted among 95 CRF patients undergoing haemodialysis in the month of February to March and analysis was done by using descriptive and inferential statistics. Karl Pearson's coefficient of correlation was used to compute the co-relation between knowledge \& Quality Of Life. Results: Among the selected 95 patients, Karl Pearson's coefficient of correlation was found to be rxy $=0.86$ since $0<\mathrm{rxy}<1$, there is positive correlation between the knowledge of self-care measures and Quality Of Life. Conclusion: The study finding revealed that there is positive correlation between the knowledge and quality of life. As the level of knowledge increases, quality of life improves simultaneously.
\end{abstract}

Keywords: chronic kidney diseases $\bullet$ chronic renal failure $\bullet$ CRF $\bullet$ quality of life

\section{INTRODUCTION:}

Chronic diseases present a significant challenge to $21^{\text {st }}$ century global health policy. ${ }^{1}$ The rapid rise of common risk factors such as diabetes,

\footnotetext{
a - Lecturer

b - Assistant Professor

c - College of Nursing, Lumbini Medical College, Palpa, Nepal

$\mathrm{d}$ - Department of Surgery

Lumbini Medical College Teaching Hospital, Palpa, Nepal
}

Corresponding Author:

Ms. Sarita Shah

e-mail: sarita.sanjeev@ymail.com

How to cite this article:

Shah S, Pokharel N. Knowledge regarding self care measures and quality of life among patients with chronic renal failure undergoing hemodialysis. Journal of Lumbini Medical College. 2013;1(1):39-42. doi:10.22502/jlmc.v1i1.12. hypertension and obesity especially among the poor, will result in even greater and more profound burdens that developing nations are not equipped to handle. Attention to chronic diseases, chronic kidney disease in particular, has been lacking, largely due to the global health community's focus on infectious diseases and lack of awareness. CKD is a worldwide health problem. According to World Health organization (WHO) Global Burden of Disease project, diseases of the kidney and urinary tract contribute to global burden with approximately 850,000 deaths every year and 115,010,107 disability adjusted life years. CKD is $12^{\text {th }}$ leading cause of death and $17^{\text {th }}$ cause of disability. ${ }^{2}$ This global prevalence, however, may be grossly underestimated for a number of reasons. Patients with CKD are at high risk for cardiovascular disease (CVD) and cerebrovascular disease (CBVD), and 
they are more likely to die of CVD than to develop end-stage renal failure. ${ }^{3}$ Moreover, patients with CVD often develop CKD during the course of their disease, which may go unrecognized. Therefore, an unknown proportion of people whose death and disability attributed to CVD have kidney disease as well. ${ }^{4}$ Renal failure is the inability of the kidneys to adequately filter metabolic waste products from the blood. Kidney failure has many possible causes. Some lead to a rapid decline in kidney function (acute kidney failure); others lead to a gradual decline in kidney function (chronic kidney failure, also called chronic kidney disease). In addition to the kidneys being unable to filter metabolic waste products (such as creatinine and urea nitrogen) from the blood, the kidneys are less able to control the amount and distribution of water in the body (fluid balance) and the levels of electrolytes (sodium, potassium, calcium, phosphate) in the blood. ${ }^{5} \mathrm{CKD}$ affects 500 million people worldwide. The number of dialysis patients increase by $7 \%$ annually. ${ }^{6}$ The burden and magnitude of chronic kidney disease (CKD) is enormous especially in developing countries. ${ }^{7}$ Lifestyle related diseases are important causes of increased morbidity and mortality in the world today. The calculations by the USRDS (United States Renal Data System, 1999), indicate that 110 of every 100,000 people have ESRD. ${ }^{6,7}$ About 29 of every 100,000 are diagnosed with ESRD each year. The availability and quality of dialysis programmes largely depend on the prevailing economic conditions and social support. ${ }^{8}$ The management of ESRD in India is largely guided by economic considerations. ${ }^{5,8}$ Treatment of ESRD in India is a low priority for cost strapped public hospitals and in the absence of health insurance plans, less than $10 \%$ of all patients receive any kind of renal replacement therapy. ${ }^{9}$ To determine which residents at risk for CKD may be in the early stages of the disease, a simple, cost-effective diagnostic tool is needed. The urine albumin test, which detects micro albuminuria, is the most sensitive test for detecting early-stage CKD. ${ }^{10}$ Haemodialysis significantly and adversely affects the lives of patients, both physically and psychologically. ${ }^{11}$ The global influence on family roles, work competence, fear of death, and dependency on treatment may negatively affect quality of life and exacerbate feelings associated with a loss of control. ${ }^{12}$ The treatment involves circulating the patient's blood outside of the body through an extracorporeal circuit (ECC), or dialysis circuit. $^{13}$

End-stage renal disease and its treatment profoundly affect health related quality of life not only for the patient but the family also. ${ }^{14}$ Although renal replacement therapy ameliorates some of the symptoms of end-stage renal disease they may not be completely alleviated. ${ }^{15}$ Moreover, with treatment often comes significant life style changes, all of which impact on quality of life. ${ }^{16}$ Quality of life of patients with end renal disease is influenced by the disease itself and by the type of replacement therapy. ${ }^{17}$ Dialysis must be repeated frequently and continued life-long until death or transplant. ${ }^{18}$ The burden of pain and other physical and mental symptoms, as previously mentioned, can account for more than one-third of the impairment observed in mental HR QOL in dialysis patients. ${ }^{19}$ Depression in CKD is likely multifactorial, though is typically attributed to feelings of loss and dependence. ${ }^{20}$ Although depression can occur at any time during the course of CKD, there are times of increased likelihood of a depressive episode, such as the time leading up to and the first year following initiation of dialysis, particularly if kidney transplantation is not an option due to advanced age and/or co morbidity. ${ }^{21}$ During this period, patients are required to make decisions regarding treatment modality and to make multiple and radical lifestyle changes, all of which impact their occupation, familial role, relationships, and leisure activities. ${ }^{22}$ They are expected to assimilate information that is foreign and frightening. ${ }^{23}$

\section{METHODS:}

The research design used for the present study is descriptive correlational design. Settings are the more specific places where data collection occurs based on the nature of the research question and the type of information needed to address it. The setting planned for this particular study is selected in Dialysis Unit of KLES Dr. Prabhakar Kore Hospital and MRC, Belgaum- Karnataka. In the present study the sample population consists of CRF patient undergoing Haemodialysis in the hospital with a sample size of 95 CRF patients. Based on the criteria mentioned, purposive sampling was used to select the sample according to the purpose of the study. Purposive sampling is non-probability sampling, in which it entails the use of the most conveniently available people or objects as subjects in a study. The tool used for gathering relevant data was a structured questionnaire on knowledge of self care measures and WHO QOL-BREF scale among CRF patient undergoing Haemodialysis. The research investigator obtained ethical clearance and formal permission from the Medical Director, K.L.E.S Dr. Prabhakar Kore Hospital and MRC, Belgaum, Karnataka to collect data for the main study. The main study was conducted at K.L.E.S Dr. Prabhakar Kore Hospital and MRC, Belgaum, from $24^{\text {th }}$ February 2011 to $5^{\text {th }}$ March 2011.The steps used for data collection was as follows:

Step-1 The investigator obtains permission from respective authority to conduct the study. 
Step-2 Selection of subjects.

Step-3 Self introduction of the investigator.

Step-4 Administration of structured knowledge questionnaire.

Step-5 Administration of WHOQOL-BREF Scale.

Step-6 Data were tabulated and analyzed.

The data obtained were analyzed in terms of the objectives of the study using descriptive and inferential statistics. The plan of the data analysis was as follows.

- Organize the data on master sheet.

- Compute frequency, percentage, mean, standard deviation and range to describe the data.

- Classify the knowledge scores as follows

$$
\begin{aligned}
& \text { *Good }(\overline{\mathrm{x}}+\mathrm{SD}) \text {, } \\
& \text { *Average }(\overline{\mathrm{x}}-\mathrm{SD} \text { to } \overline{\mathrm{x}}+\mathrm{SD}) \text {, } \\
& \text { *Poor }(<\overline{\mathrm{x}}-\mathrm{SD}) \text {; }
\end{aligned}
$$

where $\overline{\mathrm{x}}$ is Mean and SD is Standard Deviation.

Conclusion were drawn from inferential statistics. Karl Pearson's coefficient of Correlation is used to find out the relationship between knowledge of selfcare measures and Quality of life.

\section{RESULTS:}

Majority of the patients 41(43.15\%) belonged to age group of 52-72 years, and a minimum of 6 (6.31\%)patients belonged to age group of 73-93years. $76(80 \%)$ were male, and a minimum of $19(20 \%)$ patients were female. 25 (26.31\%) had business, and minimum 8 (8.42\%) patients were unemployed. 27 (28.42\%) had primary education, and a minimum of $1(1.05 \%)$ patient had no formal education. Majority of the patient's family income/month, 50 (52.63\%) had Rs $>8000$, and minimum 8 (8.42\%) patient had Rs. < 2000. 57 (60\%) belonged to the urban area, and a minimum of $38(40 \%)$ patients belonged to rural area. 66 (69.47\%) belonged to nuclear family, and a minimum of, 5 (5.26\%) patients belonged to extended family. Majority of patients 83 (87.36\%) were married, and a minimum of $2(2.10 \%)$ patients were widows. The relationship between knowledge of self care measures and quality of life were analyzed by Karl Pearson's coefficient of correlation method, and it was found that there was positive correlation between knowledge of self care measures and quality of life. It indicated that the quality of life of CRF patients undergoing haemodialysis was influenced by their level of knowledge. Karl Pearson's coefficient of co-relation was used to compute the corelation between knowledge \& Quality of Life and was found to be rxy $=0.86$. Since $0<\operatorname{rxy}<1$, there is positive correlation between the knowledge of selfcare measures\& Quality Of Life.

\section{DISCUSSION:}

Findings related to the socio-demographic variables among CRF patients undergoing hemodialysis:

Majority of the patients 41 (43.15\%) belonged to age group of 52-72 years, and a minimum of $6(6.31 \%)$ patients belonged to the age group of 73-93 years. These findings are similar to a cohort study done at Winthrop University Hospital, Mineola, New York USA7. 76 (80\%) were male, and a minimum of 19 (20\%) patients were female. Majority of patient's occupation 25 (26.31\%) was business, and a minimum of $8(8.42 \%)$ patients were unemployed. These findings were similar to the findings of the study conducted by Atlantic Health Sciences Corporation, Saint john, New Brunswick, Canada in 2004. ${ }^{2} 27$ (28.42\%) had primary education, and a minimum of $1(1.05 \%)$ patient had no formal education. These findings were similar to the findings of the study conducted at Meran School of medicine, Seljuk University, Konya Turkey. ${ }^{4}$ Majority of the patients family income/month 50 (52.63\%) was Rs. $>8000$, and a minimum of $8(8.42 \%)$ patients was $<2000$. These findings were similar to the findings of the study done at Sao Paulo University Brazil.12 57 (60\%) belonged to urban area, and a minimum of $38(40 \%)$ patients belonged to rural area. These findings were similar to the findings of the study conducted at Department Of Nursing, Kyungbok College, Pocheon, Korea. ${ }^{21} 66$ (69.47\%) belonged to nuclear family, and a minimum of $5(5.26 \%)$ patients belonged to extended family. These findings were similar to the findings of the study done at Kasha, Isfahan, Iran. ${ }^{20}$ Majority of the patients 83 (87.36\%) were married, and a minimum of $2(2.10 \%)$ patients were widows. These findings were similar to the findings of the study done at the University of Granada, Spain. ${ }^{17}$

Findings related to knowledge scores among CRF patients undergoing haemodialysis:

The assessment of knowledge of CRF patients regarding self care measures revealed that majority of $62(65.26 \%)$ had an average level of knowledge, 22 (23.15\%) had a poor level of knowledge. Whereas 11 (11.57\%) had a good level of knowledge. Area wise mean percentage knowledge levels indicate that in the area of self care measures was $53.15 \%$, introduction of CRF was $46.87 \%$, diagnostic evaluation was $40 \%$, complication was $38.42 \%$, treatment was $26.31 \%$, clinical features was $22.63 \%$.

Findings related to quality of life among CRF patients undergoing haemodialysis: 
Reveals that raw scores were the highest among Domain 4 (environmental) for all 95 patients with CRF i.e. 1118, which means they showed high quality of life in this domain. They fared better in domain 1 (physical) where raw scores were 1116 and domain 2 (psychological) where raw scores were 1100 . They fared the least in domain 3 (social relationship) where they scored 1065 and QOL was the least in this domain. The raw and transformed scores as per scoring manual for physical psychological, social relationship and environmental domain were (648-1608), (540-2257), (1416-6472) and (589-1261) respectively. These findings were similar to the findings of the study done at Taiwan. ${ }^{18}$

Findings related to relationship between knowledge of self care measures and quality of life among CRF patient undergoing haemodialysis:

The relationship between knowledge of self care measures and quality of life were analyzed by Karl Pearson's coefficient of correlation method, and it was found that there was positive correlation between knowledge of self care measures and quality of life (rxy $=0.86$ ). It indicated that the quality of life of CRF patients undergoing haemodialysis was influenced by their level of knowledge. These

\section{REFERENCES:}

1. Gillanders S, Wild M, Deighan C, Gillanders D. Emotion regulation, affect, psychosocial functioning, and wellbeing in hemodialysis patients. Am J Kidney Dis. 2008;51(4):651-62.

2. Varughese S, John GT, Alexander S, Deborah MN, Nithya N, Ahamed I et al. Pre-tertiary hospital care of patients with chronic kidney disease in India. Ind J Med Res. 2007;126:28-33.

3. Bataclan RP, Dial MA. Cultural adaptation and validation of the Filipino version of Kidney Disease Quality of Life - Short Form (KDQOL-SF version 1.3). Nephrology (carlton).2009;14: 663-8.

4. Rebollo P, Ortega F. New trends on health related quality of life assessment in end-stage renal disease patients. Int Urol Nephrol. 2002;33(1):195-202.

5. Ballal HS. The burden of chronic kidney disease in a developing country, India. Quest. 2007;9:12-9.

6. Manns BJ, Walsh MW, Culleton BF, Hemmelgarn B, Tonelli M, Schorr $M$ et al. Nocturnal hemodialysis does not improve overall measures of quality of life compared to conventional hemodialysis. Kidney Int. 2009;75:542-9.

7. Narula AS. Chronic Kidney Disease : The Looming Threat. MJAFI. 2008;64:2-3.

8. Eskridge MS. Hypertension and chronic kidney disease: the role of lifestyle modification and medication management. Nephrol Nurs J. 2010;37(1): 55-60, 99.

9. Kosmadakis GC, Bevington A, Smith AC, Clapp EL, Viana JL, Bishop NC, Feehally J. Physical exercise in patients with severe kidney disease. Nephron Clin Pract. 2010;115(1):c7-c16.

10. Segura-Orti E. Exercise in haemodialysis patients: a literature systematic review. Nefrologia. 2010;30(2):236-46.

11. Gotch F, Levin NW, Kotanko P. Calcium balance in dialysis is best managed by adjusting dialysate calcium guided by kinetic modeling of the interrelationship between calcium intake, dose of vitamin D analogues and the dialysate calcium concentration. Blood Purif. 2010;29(2):163-76.

12. Finkelstein FO, Wuerth D, Finkelstein SH. An approach to addressing depression in patients with chronic kidney disease. Blood Purif. 2010;29(2):121-4.

13. Wyszomierska A, Puka J, Myszkowska-Ryciak J, Narojek L. The period of dialysis and nutritional habits of patients with the end stage renal disease. Rocz Panstw Zakl Hig. 2009;60(3):289-92.

14. Musso CG, Michelangelo H, Reynaldi J, Martinez B, Vidal F, findings were similar to the findings of the study done at Sivas, Turkey. ${ }^{24}$

\section{CONCLUSION:}

The study emphasizes on the need for improving knowledge in patients and their care givers in which the health personnel can update their knowledge and skills to provide quality nursing care. The study finding revealed that there is positive correlation between the knowledge and quality of life. As the level of knowledge increases, quality of life improves simultaneously. Nurse administrator can encourage nursing personnel, patients and care givers to make active contribution towards the proper gain of knowledge. Nurse administrator can help prepare skilled nurses, health workers and employees in handling dialysis machines to provide quality of care. The findings of the study have implications for nursing practice, nursing education, nursing administration and research. Since present study showed that most of the patients had average knowledge which can be improved by nurses by providing teaching strategy, it helps in uplifting patients' knowledge and hence improvement in their quality of life.

Quevedo M. Combination of oral activated charcoal plus low protein diet as a new alternative for handling in the old end-stage renal disease patients. Saudi J Kidney Dis Transpl. 2010;21(1):102-4.

15. Hamissi J, Porsamimi J, Naseh MR, Mosalaei S. Status of hemodialyzed patients with chronic renal Failure. East Afr J Public Health. 2009;6:108-11.

16. Koh KP, Fassett RG, Sharman JE, Coombes JS, Williams AD. Effect of intradialytic versus home-based aerobic exercise training on physical function and vascular parameters in hemodialysis patients: a randomized pilot study. Am J Kidney Dis. 2010;55(1):88-99.

17. MacLaughlin HL, Cook SA, Kariyawasam D, Roseke M, van Niekerk M, Macdougall IC. Nonrandomized trial of weight loss with orlistat, nutrition education, diet, and exercise in obese patients with CKD: 2-year follow-up. Am J Kidney Dis. 2010;55(1):69-76.

18. Alavi NM, Aliakbarzadeh Z, Sharifi K. Depression, anxiety, activities of daily living and quality of life scores in patients undergoing renal replacement therapies. Transplant Proc. 2009;41:3693-6.

19. Mafra D, Jolivot A, Chauveau P, Drai J, Azar R, Michel C et al. Are gherlin and leptin involved in food intake and body mass index in maintenance hemodialysis? J Ren Nutr. 2010; 20(3):151-7.

20. Milovanov IuS, Lysenko LV, Milovanova LIu, Dobrosmyslov IA. The role of balanced low-protein diet in inhibition of predialysis chronic kidney disease progression in patients with systemic diseases. Ter Arkh. 2009;81(8):52-7.

21. Sanchez C, Aranda P, Perez de la Cruz A, Llopis J. Magnesium and zinc status in patients with chronic renal failure: influence of a nutritional intervention. Magnes Res. 2009;22(2):72-80.

22. Ranganathan N, Friedman EA, Tam P, Rao V, Ranganathan P, Dheer R. Probiotic dietary supplementation in patients with stage 3 and 4 chronic kidney disease: a 6-month pilot scale trial in canada. Curr Med Res Opin. 2009;25(8):1919-30.

23. Reddy V, Symes F, Sethi N, Scally AJ, Scott J, Mumtaz R et al. Dietitian-led education program to improve phosphate control in a single-center hemodialysis population. J Ren Nutr. 2009;19(4):314-20.

24. Tsutsui $\mathrm{H}$, Koike T, Yamazaki C, Ito A, Kato F, Sato $\mathrm{H}$ et al Identification of hemodialysis patients' common problem using the International classification of functioning, Disability, and Health. Ther Apher Dial. 2009;13(3):186-92. 